\title{
Concept of Direct Perception in Ayurveda
}

\author{
Dilip Kumar G* \\ Department of Agada Tantra and Vidhi Ayurveda, Government Ayurvedic College, \\ India \\ *Corresponding author: Dilip Kumar Goswami, Department of Agada Tantra and

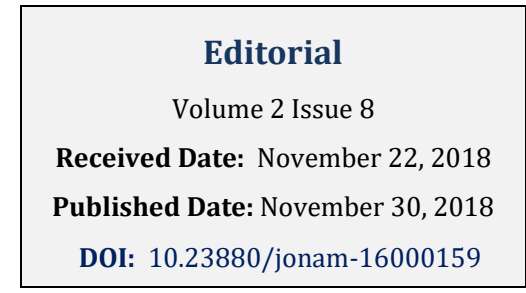

Vidhi Ayurveda, Government Ayurvedic College, India, Tel: 09864351115; Email: drdilipgoswami37@gmail.com

\section{Editorial}

"Direct perception" literally means "The Ability to Notice or Understand Something". Any knowledge, when perceived by the sense organs, is considered as direct perception. In the Ayurvedic classics a concept of "PRATYAKSHYA" is found. "PRATYAKSHYA" is a Sanskrit word that literally means "that which is perceptible to the eye or visible, in general usage it refers to being present before the eye i.e. within the range of sight, cognizable by any sense organ, distinct, evident, clear, direct, immediate, explicit, express, corporeal [1].

Any fact which is to be proved to be scientific it must be either seen by the eyes, heard by the ears, tasted by the tongue, smelled by the nose or touched by the skin. With the help of the sense organs directly we develop the idea of existence of the substances. For each and every substance, after study and analysis with the application of laboratory tests, some properties are identified and fixed which are accepted universally to separate it from the others.

Ayurvedic scholars, especially the father of Indian Medicine "CHARAKA" mentions "PRATYAKSHYA" as one of the four fold methods of investigation [2]. As defined by Charaka direct observation (Pratyaksha) is a situation of acquiring knowledge as a result of combination of the soul (Atma), Sense organs (Indriya), Mind (Mana) and the object (Artha) [3]. It clearly shows that, only by seeing an object with the eyes knowledge cannot be acquired. For that healthy soul and mind must be with the person.

Ayurveda says that, a physician must examine the patient with his perfectly sound soul and mind to get the proper information about the disease and the diseased. Any agony or imbalance in any one of them will cause mistake in the process. Classical description of the process of acquiring direct knowledge is critical though mentioned briefly. There is ampoule of scope to study on the point.

An interesting fact regarding the direct observation as mentioned in Charaka Samhita is "exceptions of direct observation (Pratyakshanupalabdhi)" [4]. This concept reflects the minute and scientific feelings of the ancient Indian scholars. Charaka says that, even if the object is there then also its existence cannot be perceived due to the following factors:

1. If it is too near to the person (Atisannikarshat): It is scientifically proved that, the sense organs need a minimum distance of the substance of which the knowledge is to be perceived. Due to excessive closeness they cannot perceive the actual knowledge.

2. If it is far away from the person (Atibiprakarshat): After a limited distance the organs cannot perceive the knowledge of existence of an object.

3. If the substance is kept under cover (Avaranat): As the covering keeps the actual object the knowledge cannot be acquired.

4. If there is weakness of the sense organ (Karanadaurvalyat): An week organ cannot acquire the knowledge of the substance.

5. If the mind is not stable (Manoanavasthanat): If at the time of observing the object the person suffers from mental agony, anxiety, fear, etc. then the complete knowledge cannot be gained .

6. If there are many things of same character in one place (Samanabhiharat): Among huge number of objects containing almost same character it becomes difficult to gain the appropriate knowledge ,

7. If the substance remains pressed by another substance (Abhibhavat): Pressure of another object 


\section{Journal of Natural \& Ayurvedic Medicine}

reduces the visually of the target object and the process of acquiring actual knowledge is hampered.

8. If the substance is very small (Atisoukshmyat): As established by the studies it is proved that, the sense organs need an optimum size or intensity of the objects in lack of which the knowledge of it's existence cannot be gained.

The concept of direct observation in the Ayurvedic classics is definitely praisable and it must be confessed that, the idea of "exceptions of direct observation" is a unique concept of Ayurveda.

\section{References}

1. Nico Ditch (2018) Today's featured article.

2. (2014) Charaka Samhita, Sutrasthana, chapter-11, Sloka-17.

3. (2018) Charaka Samhita, Sutrasthana, Chapter-11, Sloka-20.

4. (2013) Charaka Samhita, Sutrasthana, Chapter-11, Sloka-8. 